\title{
(Research Article) \\ Parametric Optimization of Face Milling to Improve Surface Roughness using AISI 1010 Steel
}

\author{
Aakash N. Samani ${ }^{1 *}$, Prof. Parag Paija ${ }^{2}$ \\ ${ }^{1 * 2}$ Department of Mechanical Engineering, B.H. Gardi College of Engineering \& Technology, Gujarat Technological University, Rajkot, India
}

\begin{abstract}
Milling is the machining process of using rotary cutters to remove material from a workpiece by advancing in a direction at an angle with the axis of the tool. It covers a wide variety of different operations and machines, on scales from small individual parts to large, heavy-duty gang milling operations. It is one of the most commonly used processes in industry and machine shops today for machining parts to precise sizes and shapes. Face Milling is the most common milling operation and can be performed using a wide range of different tools. Cutters with a 45-degree entering angle are most frequently used, but round insert cutters, square holder cutters and side and face mills are also used for certain conditions. This study has been undertaken to investigate the optimum parameter using Design of Experiments through Taguchi method to improve surface roughness of AISI 1010 steel in the milling process using L27 Orthogonal array. In this work an attempt has made to find optimum cutting parameters in Milling Machine from Spindle Speed, Feed \& Depth of Cut to improve Surface Roughness with the help of Vertical Machining Centre Batliboi for a Specific material AISI 1010 Steel (commonly known as Black Bar). The Results obtained with Roughness tests though Roughness Tester(Mitutoyo) are Validated with the help of Minitab Software.
\end{abstract}

Keywords - Milling, Surface Roughness, Taguchi, S/N Ratio, ANOVA, Parametric Optimization.

\section{Introduction}

Roughness is very good predictor in performance of mechanical parts since there are irregularities in surface may form nucleation sites for cracks or corrosion [1]. It is difficult and expensive to control during manufacturing. In Face milling of steel, it is found that parameters like feed rate, cutting speed and depth of cut influence surface roughness and tool vibrations [2].

Researchers mainly focused on determining the cutting force, tool wear and surface roughness if the milling process. Some results suggested that reduction in tool vibrations reduce the level of surface roughness. Objective is to set optimum parameters using HSS tool on AISI 1010 Steel using different variable parameters with minimum possible Surface roughness.

*Corresponding Author: e-mail: samaniaakash@gmail.com ISSN 2320-7590

(C) 2018 Darshan Institute of Engg. \& Tech., All rights reserved

\section{Design of experiments}

Design of Experiments is a statistical method to resolve complex and costly situations with considering minimal number of experiments and the results to be verified by statistical methods [3]. DOE provides breakthrough improvements in product quality and process efficiency. With respect to manufacturing terms when we consider numbers of variables we can narrow the experiments to minimal numbers. Thus, we can maintain the most important information with performing few experiments. The most important process of DOE is determining independent variables values at which experiments are to be performed. DOE is fundamentally divided into four parts. They are:

1. Planning Phase

2. Designing Phase

3. Conducting Phase

4. Analyzing Phase

Planning Phase consists problem recognition and formulation. Development of few new Products; Improvements of existing processes or products, Improvements or the process/product performance with needs 
of customers and Reduction of existing Process speed related Problems carried out in Planning Phase.

In Designing Phase user selects most appropriate Design of experiment. Experiments can be statistically designed by Orthogonal approach array by Taguchi method, ANOVA method, within which one can pick full factorial, partial factorial. Size of experiments is dependent on number of factors to be chosen and numbers of level of each factor.

Conducting Phase involves trial experiments to be carried out and evaluation of results. Some considerations are need to be studied before are Selection of Suitable location for carrying out experiments which is not affected by external source i.e. vibration, atmosphere, etc.

After the Experiments in Conducting Phase results are verified by assessing the outcomes and analyzing the derived conclusions. Objectives to be achieved are Determining that Design parameters or variables that affect the means process performance, Influence performance variability and chances of further improvements.

\section{Taguchi methodology}

The Taguchi technique from Dr. Genichi Taguchi [4], a Japanese Engineer is a guide and reference for many Industrialists, Engineers, Scientists which is essential improvement technique for product or process experimentation or development.

In 1940 after first world war Japanese established Electrical Communication Laboratory(ECL) with Dr. Genichi Taguchi to improve their poor and totally unsuitable longdistance communication purpose and enhancing product quality. Dr. Taguchi started new methods to optimize the process of engineering experimentations. He developed techniques, which we now know as 'Taguchi Techniques.

It's a great philosophy for quality control in manufacturing industries. Its work is creating entire genre of engineers who believes in quality. The consequences are far from this philosophy and founded on three simple and fundamental concepts.

- Quality should be designed into the product, not inspected.

- Best Quality is achieved by minimizing the deviations from target. The Product design should be immune to uncontrollable environmental factors.

- Quality cost should be measured as a function of deviation from standard and losses should be system wide.

These three are principles of the quality measures and he also recommended three-stage procedure as below.
- Concept Design: Science and Engineering knowledge is used to generate basic process or product design.

- Parameter Design: In these Stage different parameters related to process is selected and studied to minimize performance variation.

- Tolerance Design: In these stage tolerance of process conditions and sources of variability are set.

\section{Selection of variables}

Among The different parameters such as tool geometry, speed, feed, depth of cut, coolant flow rate selected parameters for experiments are Cutting Speed, Feed Rate and Depth of Cut. In L27 orthogonal array Levels for each variable are 3[5].

As there is also dry milling is also used without the effect of coolant in some process and due to the low depth of cut it would not be such hard effect of load which needs cooling so coolant flow rate is not considered in this Selection of Variables, though it might be considerable in future aspect.

Table 1. Process Parameters and their Levels

\begin{tabular}{|c|c|c|c|}
\hline Process Parameter & L1 & L2 & L3 \\
\hline Spindle Speed(RPM) & 1200 & 1600 & 2000 \\
\hline Feed Rate(mm/min) & 50 & 75 & 100 \\
\hline Depth of Cut(mm) & 0.50 & 0.10 & 0.15 \\
\hline
\end{tabular}

\section{Experimental setup}

The Experiments were carried out at NSIC (National Small Industries Corporation) Rajkot where Batliboi Trainer VMC (Vertical Machining Centre) was used to carry out experimental setup.

Specifications of Machine are:

- Maximum Travel on $X$ axis $\quad: 200 \mathrm{~mm}$

- Maximum Travel on Y axis $: 125 \mathrm{~mm}$

- Maximum Travel on $\mathrm{Z}$ axis $\quad: 200 \mathrm{~mm}$

- Maximum Spindle Speed $\quad$ : 2000 RPM

- Spindle Taper : BT 30

- Accuracy : $: 10 \mu \mathrm{m}$ 


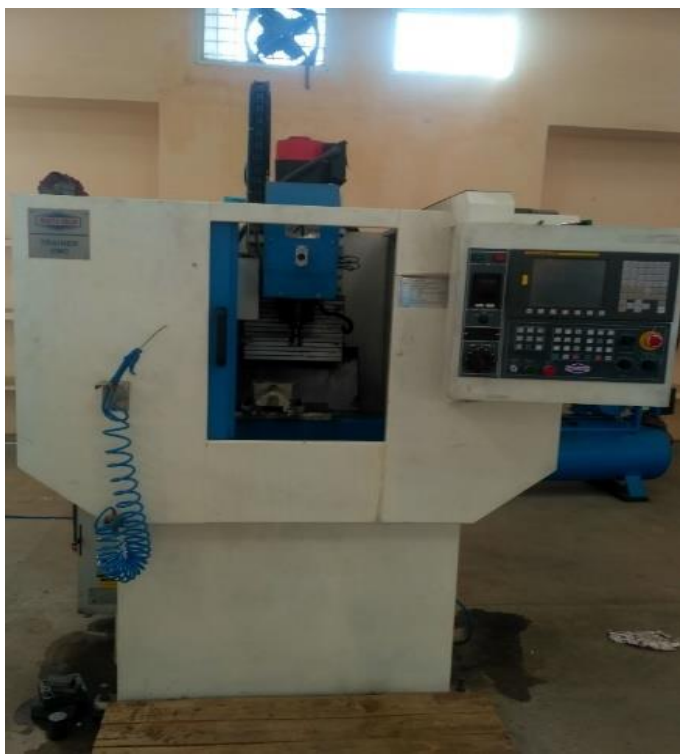

Figure 1. Baltiboi VMC

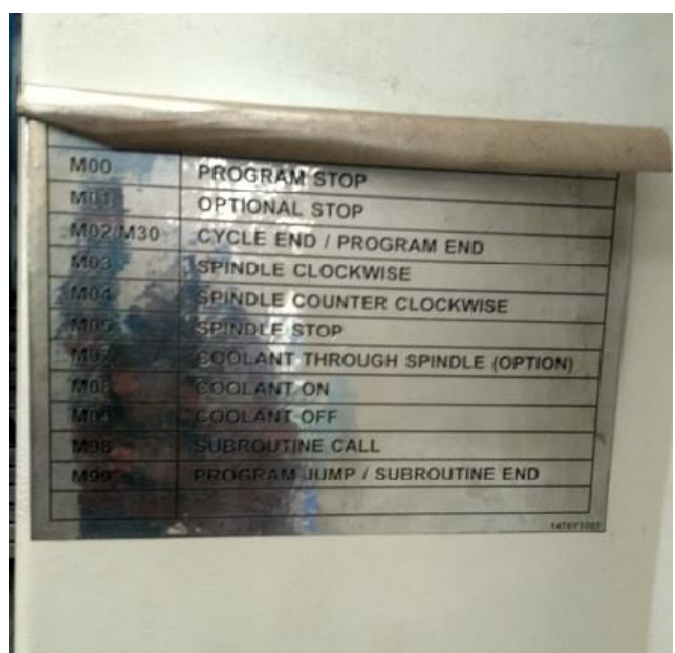

Figure 2. FANUC Controller

For Tool selection there's different types of cutter available in market such as Side Face Cutter, End Mill, Insert Edge Cutters etc. To Carry out these experiments Insert Edge cutter of $50 \mathrm{~mm}$ diameter was selected according to the requirement of the cutting size with the considerations of Industrial use.

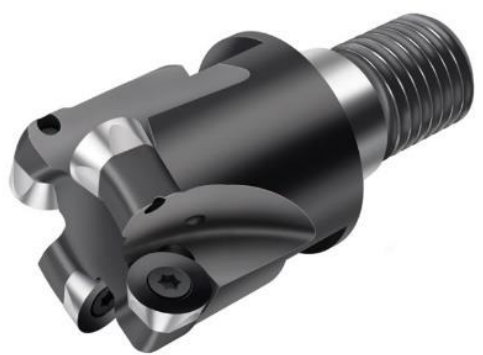

Figure 3. Insert Cutter
$\mathrm{R}_{\mathrm{a}}$ is the arithmetic average of the absolute values of the roughness profile ordinates, also known as Arithmetic Average (AA), Centre Line Average (CLA) [6]. The average roughness is the area between the roughness profile and its mean line, or the integral of the absolute value of the roughness profile height over the evaluation length. Roughness is measured in $\operatorname{microns}(\mu \mathrm{m})$

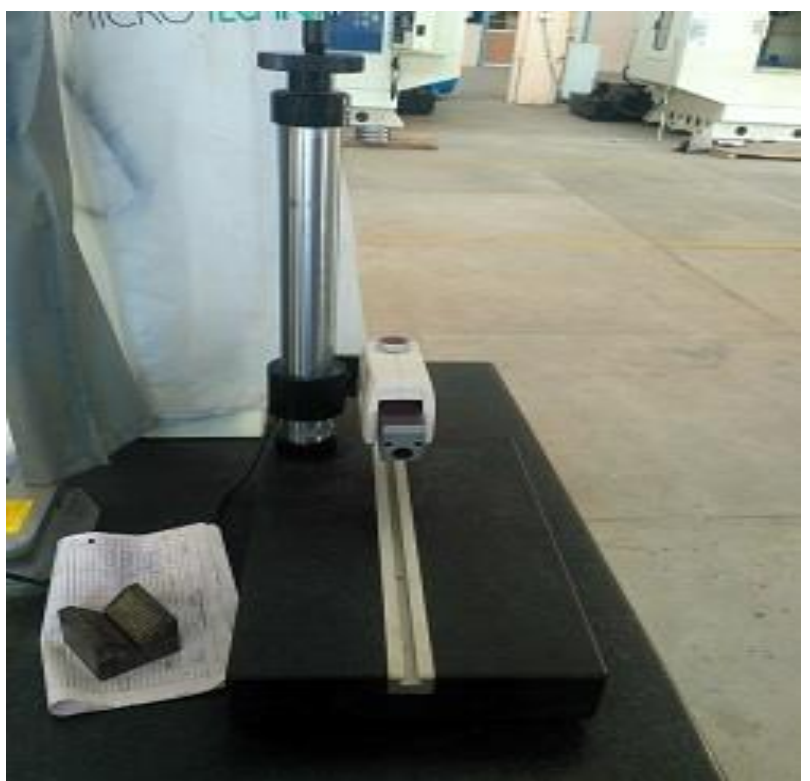

Figure 4. Mitutoyo Ra Tester

\section{Experimental design}

The Experiments were designed according to Taguchi's Design of Experiments under the selection of three levels of three factors chosen which were Spindle Speed, Feed Rate and Depth of Cut and The Roughness tests were concluded after measuring through the Mitutoyo Roughness tester (Fig 4) recorded in Table 2 and also the experiments are conducted for partial factorial design [7]. Figure 5 contains few selected experimental plates on which the experiments were carried out.

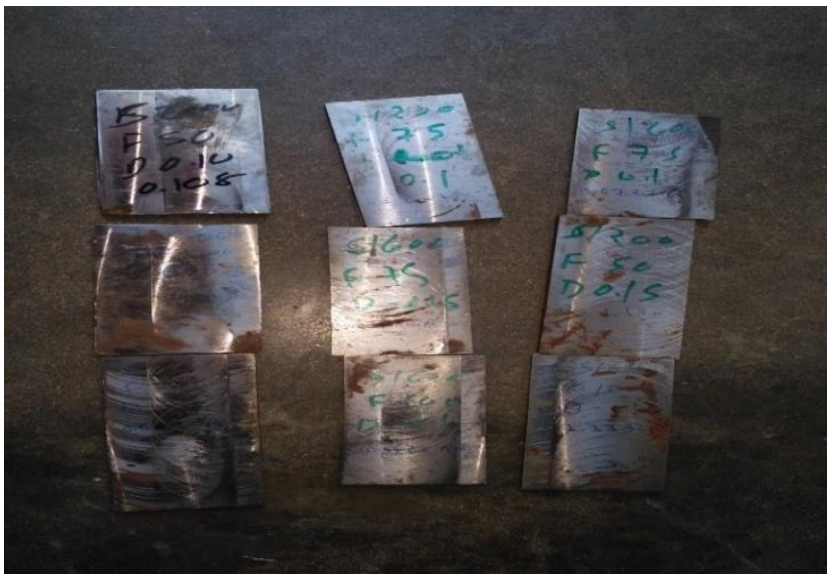

Figure 5. Trail Experiments 
Table 2. Experimental Design

\begin{tabular}{|c|c|c|c|c|}
\hline $\begin{array}{c}\text { Experiment } \\
\text { No. }\end{array}$ & $\begin{array}{c}\text { Speed } \\
(\mathrm{RPM})\end{array}$ & $\begin{array}{c}\text { Feed Rate } \\
(\mathrm{mm} / \mathrm{min})\end{array}$ & $\begin{array}{c}\text { Depth of } \\
\text { Cut }(\mathrm{mm})\end{array}$ & $\mathrm{RA}(\mu \mathrm{m})$ \\
\hline 1 & 1200 & 50 & 0.50 & 0.198 \\
\hline 2 & 1200 & 50 & 0.10 & 1.822 \\
\hline 3 & 1200 & 50 & 0.15 & 1.120 \\
\hline 4 & 1200 & 75 & 0.50 & 1.780 \\
\hline 5 & 1200 & 75 & 0.10 & 0.239 \\
\hline 6 & 1200 & 75 & 0.15 & 0.449 \\
\hline 7 & 1200 & 100 & 0.50 & 1.557 \\
\hline 8 & 1200 & 100 & 0.10 & 1.542 \\
\hline 9 & 1200 & 100 & 0.15 & 2.456 \\
\hline 10 & 1600 & 50 & 0.50 & 1.578 \\
\hline 11 & 1600 & 50 & 0.10 & 1.356 \\
\hline 12 & 1600 & 50 & 0.15 & 0.884 \\
\hline 13 & 1600 & 75 & 0.50 & 0.392 \\
\hline 14 & 1600 & 75 & 0.10 & 0.672 \\
\hline 15 & 1600 & 75 & 0.15 & 0.705 \\
\hline 16 & 1600 & 100 & 0.50 & 0.664 \\
\hline 17 & 1600 & 100 & 0.10 & 0.552 \\
\hline 18 & 1600 & 100 & 0.15 & 1.115 \\
\hline 19 & 2000 & 50 & 0.50 & 0.119 \\
\hline 20 & 2000 & 50 & 0.10 & 0.108 \\
\hline 21 & 2000 & 50 & 0.15 & 0.188 \\
\hline 22 & 2000 & 75 & 0.50 & 0.175 \\
\hline 23 & 2000 & 75 & 0.10 & 0.298 \\
\hline 24 & 2000 & 75 & 0.15 & 0.300 \\
\hline 25 & 2000 & 100 & 0.50 & 0.380 \\
\hline 26 & 2000 & 100 & 0.10 & 0.159 \\
\hline 27 & 2000 & 100 & 0.15 & 0.216 \\
\hline & & & & \\
\hline
\end{tabular}

\section{Optimization of machining parameters using TAGUCHI's $\mathrm{S} / \mathrm{N}$ ratio analysis}

The outcome of Experimental work of Surface Finish (Ra) is analyzed using Taguchi Design in Minitab software and $\mathrm{S} / \mathrm{N}$ ratio values are determined. The Optimum levels of influential parameters are determined based on the obtained $\mathrm{S} / \mathrm{N}$ ratios.

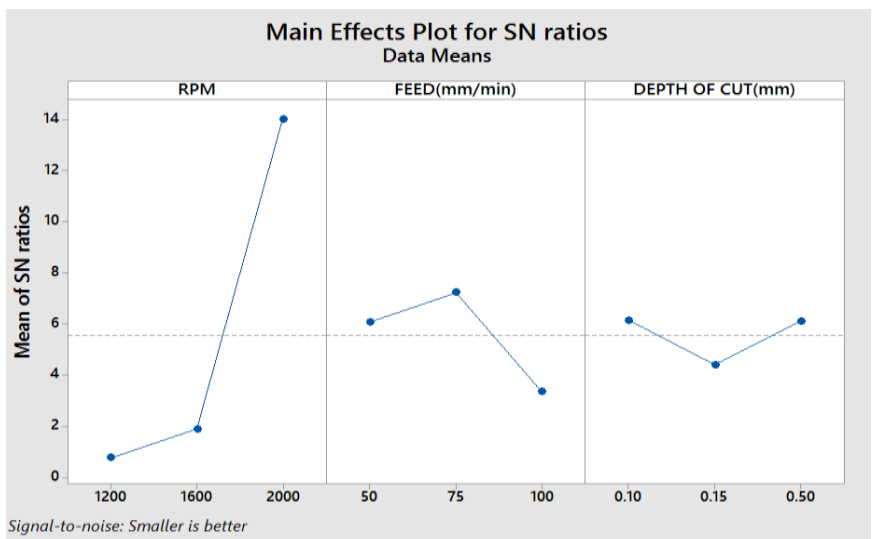

Figure 6. Main Effect Plot for S/N ratio on Surface Roughness
Table 3. Response Table for $\mathrm{S} / \mathrm{N}$ Ratios

\begin{tabular}{|c|c|c|c|}
\hline Level & $\begin{array}{c}\text { Spindle } \\
\text { Speed(rpm) }\end{array}$ & Feed (mm/min) & $\begin{array}{c}\text { Depth of Cut } \\
(\mathrm{mm})\end{array}$ \\
\hline 1 & 0.7598 & 6.0821 & 6.1460 \\
\hline 2 & 1.8807 & 7.2349 & 4.4015 \\
\hline 3 & 14.0152 & 3.3386 & 6.1082 \\
\hline Delta & 13.2555 & 3.8963 & 1.7446 \\
\hline Rank & 1 & 2 & 3 \\
\hline
\end{tabular}

The Response Table for Signal-to-Noise Ratios contains a row for the average signal-to-noise ratio for each factor level, Delta, and Rank. The table contains a column for each factor.

Delta: Delta is the difference between the maximum and minimum average response (signal-to-noise ratio or standard deviation) for the factor.

Rank: The Rank is the rank of each Delta, where Rank 1 is the largest Delta.

After assessing the $\mathrm{S} / \mathrm{N}$ ratio values (Table 3), the effect of each machining parameter is separated based on $\mathrm{S} / \mathrm{N}$ ratio at different levels and the values of $\mathrm{S} / \mathrm{N}$ ratio for each level of each factor and effect of parameter on response( $\mathrm{Ra})$ in the rank wise are summarized in Table 4[11].

Table 4. S/N Ratios

\begin{tabular}{|c|c|c|}
\hline Exp. Run & Surface Roughness Ra $(\mu \mathrm{m})$ & S/N for Ra \\
\hline 1 & 0.198 & 14.0667 \\
\hline 2 & 1.822 & -5.2110 \\
\hline 3 & 1.120 & -0.9844 \\
\hline 4 & 1.780 & -5.0084 \\
\hline 5 & 0.239 & 12.4320 \\
\hline 6 & 0.449 & 6.9551 \\
\hline 7 & 1.557 & -3.8458 \\
\hline 8 & 1.542 & -3.7617 \\
\hline 9 & 2.456 & -7.8046 \\
\hline 10 & 1.578 & -3.9621 \\
\hline 11 & 1.356 & -2.5783 \\
\hline 12 & 0.884 & 1.0710 \\
\hline 13 & 0.392 & 8.1343 \\
\hline 14 & 0.672 & 3.4526 \\
\hline 15 & 0.705 & 3.0362 \\
\hline 16 & 0.664 & 3.5566 \\
\hline 17 & 0.552 & 5.1612 \\
\hline 18 & 1.115 & -0.9455 \\
\hline 19 & 0.119 & 18.4891 \\
\hline 20 & 0.108 & 19.3315 \\
\hline 21 & 0.188 & 14.5168 \\
\hline 22 & 0.175 & 15.1392 \\
\hline 23 & 0.298 & 10.5157 \\
\hline 24 & 0.300 & 10.4576 \\
\hline 25 & 0.380 & 8.4043 \\
\hline 26 & 0.159 & 15.9721 \\
\hline 27 & 0.216 & 13.3109 \\
\hline & & \\
\hline
\end{tabular}


The formula for the smaller the better $\mathrm{S} / \mathrm{N}$ Ratio using base $10 \log$ is given by

where

$$
\mathrm{S} / \mathrm{N}=-10 \times \log \left(\Sigma\left(\mathrm{Y}_{2}\right) / \mathrm{n}\right)
$$

$\mathrm{Y}=$ responses for the given factor level combination

$\mathrm{n}=$ number of responses in the factor level combination.

Optimal combination of conditions resulting in the best possible solution. Optimization can help you find, for example, the optimal performance of a server or the best method

For the selected milling process of AISI 1010 Steel from Selected Variables on different Levels Optimal Control Parameters are listed in Table 5 to achieve best surface roughness.

Table 5: Optimum Control Parameters Values for $\mathrm{S} / \mathrm{N}$ Ratio Analysis

\begin{tabular}{|c|c|}
\hline Speed (RPM) & 2000 \\
\hline Feed Rate (mm/min) & 50 \\
\hline Depth of Cut $(\mathrm{mm})$ & 0.10 \\
\hline
\end{tabular}

\section{Optimization of impact of each parameter on process using ANOVA}

To evaluate the impact of Each Parameter on the process Analysis of Variance method is utilized and the output of the ANOVA and the Results are in the table 6 and 7 respectively [8].

Table 6. ANOVA results

\begin{tabular}{|l|c|c|c|c|}
\hline Source & DF & Contribution & F-Value & P-Value \\
\hline Speed(RPM) & 2 & $43.46 \%$ & 8.78 & 0.002 \\
\hline Feed(mm/min) & 2 & $6.74 \%$ & 1.36 & 0.279 \\
\hline DOC $(\mathrm{mm})$ & 2 & $0.28 \%$ & 0.06 & 0.945 \\
\hline Error & 20 & $49.52 \%$ & & \\
\hline Total & 26 & $100 \%$ & & \\
\hline
\end{tabular}

Table 7. Model summary

\begin{tabular}{|c|c|c|c|}
\hline S & R-sq & R-sq(adj) & R-sq(pred) \\
\hline 0.526138 & $50.48 \%$ & $35.62 \%$ & $9.75 \%$ \\
\hline
\end{tabular}

\section{Conclusions}

The Experimental Investigation on 27 experiments Table 6 from the ANOVA results shows that speed is most effective parameter using Level 3(2000 RPM) we get the best surface roughness. Taguchi's S/N ratio analysis using Minitab 18 software confirms the optimum parameters are Speed2000RPM, Feed- $50 \mathrm{~mm} / \mathrm{min}$, Depth of Cut $0.10 \mathrm{~mm}$.

With Optimization Analysis of Variance Method Contribution of each parameter on process is also evaluated which concludes the work with result the speed is having $43.46 \%$ and Feed and Depth of Cut is having $6.74 \%$ and $0.28 \%$ contribution respectively.

\section{Future scope}

After the test of ANOVA, it shows the effects of machining parameters was total $50.48 \%$ and effect of only Spindle Speed was $43.46 \%$ which could be used for improvisation in future aspects to either decrease the error range in machine which could be happening due to lots of reason in either machining or due to human error, parameter selections etc.

$\mathrm{S} / \mathrm{N}$ ratio gets higher with increase in speed which could cause the effect on Surface and roughness might be used for future study.

\section{References}

1. M. S. Sukumar, P. Venkata Ramaiah, A. Nagarjuna, "Optimization and Prediction of Parameters of Face milling of AL 6061 Using Taguchi and ANN Approach" (2014), Procedia Engineering Vol 97, 365-371

2. Bombale Ravindra Prakash, V. L. Kadlag, D. R. Mahajan, "Effect of Process Parameters on surface roughness of alloy steels while working on Milling Machine using Taguchi Technique" (2016), International Journal on Mechanical Engineering and Robotics, Vol-4, 2321-5747

3. R. Ashok Raj, T. Parun, K. Shivraj and T. T. M. Kannan, "Optimization of Milling Parameters of EN8 Using Taguchi Methodology" (2013), International Journal of Mechanical Engineering and Robotics Research, Vol-2, 2278-0149

4. Kundan Kumar, Somnath Chattopadhyaya, Hari Singh, "Optimal Material Removal and effect of process parameters of cylindrical grinding machine by Taguchi Method" (2012), International Journal of Advanced Engineering Research and Studies, Vol-2, 41-45

5. Chintan H. Patel, Chirag P. Patel, "Parametric Optimization of End Milling of AISI 1018 Mild Steel by Various Lubricants with Solid Carbide End Mills" (2013), International Journal of Engineering Research and Applications, Vol-3, 728-732

6. M. Durairaj, S. Gowri, "Parametric Optimization of Improved Tool Life and Surface Finish in Micro Turning Using Genetic Algorithm" (2013), Procedia Engineering, Vol-64, 878-887

7. Muhhamed Shihan, J. Chandra Das, M. Senthil Kumar and TTM Kannan, "Experimental Investigation and Design Optimization of Face Milling Parameters on Model K- 500 by DOE Concept" (2017), International Journal of Mechanical and Production Engineering Research and Development, Vol-7, 403-410 
8. Piyush Pandey, Prabhat Kumar Sinha, Vijay Kumar and Manas Tiwari, "Process Parametric Optimization of CNC Vertical Milling Machine Using Taguchi Technique in Varying Condition", (2013), IOSR Journal of Mechanical and Civil Engineering, Vol-6,34-42

9. Harshraj D. Wathore, P. S. Adwani, "Investigation of Optimum Cutting Parameters for End Milling of H13 Die Steel Using Taguchi based Grey Relation Analysis" (2015), International Journal of Scientific Engineering and Applied Science, Vol-1, 2395-3470

10. Lokesha, P. B. Nagaraj, P. Dinesh, "Experimental Investigation of Influence of Process Parameters on
Frictional Force and Surface Roughness During Machining of AL-6081 Material”, (2013), International Journal of Research in Engineering and Technology, Vol-5, 2321-7308

11. Mihir Patel, "Optimization of Milling Process Parameters- A review" (2015), International Journal of Advance Research in Engineering and Applied Sciences, Vol-4,2278-6252

12. Gadakh V. S., "Application of MOORA method for Parametric Optimization of milling process" (2011), International Journal of Applied Engineering Research, Vol-4, 0976-4259

\section{Biographical notes}

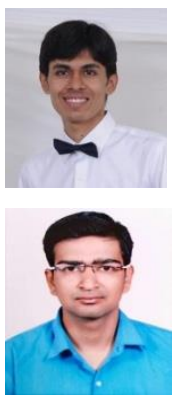

Prof. Parag Paija has received M.Tech. in CAD/CAM from Nirma University, Ahmedabad. He is Assistant Professor in Mechanical department of B. H. Gardi College of Engineering \& Technology, Rajkot, Gujarat, India.

Aakash N. Samani has completed M.E. in CAD/CAM from Gujarat Technological University in 2018. He was a student at B. H. Gardi College of Engineering \& Technology, Rajkot, Gujarat, India. 